\title{
LA ÚLTIMA VISITA DEL EMBAJADOR: UNA APROXIMACIÓN CLÍNICA COMPRENSIVA A LA EXPERIENCIA DE DUELO DE UNA MADRE POR SU HIJO EN LA CIUDAD DE MEDELLÍN ${ }^{1}$
}

\section{The Ambassador's last Visit: A Comprehensive Clinical Approach to the Mourning Experience of a Mother for her Son in the City of Medellin}

\author{
Sebastián Acosta Zapata ${ }^{2}$
}

Recibido: 2018-09-09 Aceptado: 2018-12-13
Abstract: The objective of this work is to understand, through the proposals of existential psychotherapy and phenomenology, the way in which a mother experiences grief for her child in the midst of psychological accompaniment. The research was conducted over a period of nine months with biweekly sessions. The results show that the duel is influenced by the conception of the death of the time and that its development implies the creation of a new relationship with the world and with the deceased.

Keywords: Death, mourning, maternity, phenomenological-existential psychology. fragmentación de lazos afectivos, perpetuación de la memoria, vivencia espiritual.

Palabras clave. Muerte, dolor, maternidad, psicología fenomenológico-existencial.

Para citar este artículo en APA: Acosta, S. (2019). La última visita del embajador: una aproximación clínica comprensiva a la experiencia de duelo de una madre por su hijo en la ciudad de Medellín. Revista de Psicologia Universidad de Antioquia, 11(1), ***_***.**_**. DOI: https:// doi.org/10.17533/udea.rp.v11n1a07
Artículo de investigación derivado de la Maestría en Psicología Clínica, Universidad San Buenaventura, Medellín.

2 Psicólogo, Magíster en Psicología Clínica. Correo: sacostapsico@gmail.com; https://orcid.org/0000-0001-60817272 


\section{Introducción}

El duelo se ha considerado históricamente como un proceso natural y una reacción normal ante la pérdida de un ser querido. Los profesionales que trabajan en el acompañamiento a personas en duelo se han interesado en comprender aquellas particularidades que impiden la evolución esperada del proceso y que afectan el normal desarrollo de la vida de los dolientes.

En el más reciente Manual diagnóstico y estadístico de trastornos mentales (dsm-v-tr), el duelo aparece descrito en un espectro que va desde lo "no complicado" hasta lo "complejo persistente" (2014, p. 789). Uno de los criterios que usa el manual para determinar que un duelo no es complicado - V62.82 (Z63.4) — es la apreciación de quien lo está atravesando como algo normal, es decir, que el deudo siente que su reacción es acorde con su contexto y su relación con la persona fallecida. A su vez, el dsm v-tr define el duelo complejo persistente como un trastorno relacionado con traumas y factores de estrés especificado y lo caracteriza por una "pena intensa y persistente asociada a reacción de luto” (dms v, 2014, p. 225). Esta nueva consideración del duelo es prevista por Joanneliese de Lucas Freitas (2013), quien advierte que pasar de una visión del duelo como proceso natural y transitorio a una en la que se lo entienda como susceptible de ser patológico, es razón suficiente para que se investigue y construya conocimiento en relación con el nuevo sentido del fenómeno.

Lo propuesto por Freitas cobra amplio significado cuando se da una mirada a las cifras: sólo en el Valle de Aburrá del departamento de Antioquia, territorio compuesto por diez municipios, murieron en 2017 alrededor de 19 693 personas, lo que genera una tasa de mortalidad general de 5.1 por cada mil habitantes (Seccional de Salud y Protección Social de Antioquia, 2018). La Unidad de Duelo de la Funeraria San Vicente, única ips en el territorio dedicada específicamente a la atención del duelo, asignó 1110 citas durante el año 2017 para iniciar procesos psicológicos de acompañamiento a personas que se encuentran en proceso de duelo; durante el mismo año, recibió en su conferencia semanal institucional Sobrevivir a la pérdida de un ser querido a 4.856 personas, de las cuales asistieron 654 niños (Unidad de Duelo, 2017). 
La última visita del embajador: una aproximación clínica comprensiva a la experiencia [155] de duelo de una madre por su hijo en la ciudad de Medellín

Estas cifras señalan que alrededor del $5.6 \%^{3}$ de las personas que sufrieron una pérdida durante el año en este territorio solicitaron asistencia profesional para su experiencia de duelo. Según Payás (2010), quien cita el Grief Index de Lathamn, Prigerson, Barry et al, hay un promedio de seis personas afectadas por cada muerte y aproximadamente entre un $8 \%$ y $10 \%$ requiere atención profesional a causa de su proceso de duelo; esto significa que, de mantenerse la tendencia, solamente en el Valle de Aburrá podrían surgir cada año aproximadamente 11815 casos de duelos que requieren de atención psicológica. Estas cifras, sumadas a las condiciones sociales, políticas y de seguridad de nuestro contexto, hacen que la pregunta por la experiencia del tratamiento del duelo sea, no sólo necesaria, sino fundamental para crear políticas de salud pública y diseñar programas de intervención coherentes y eficaces.

Históricamente el proceso de duelo ha interesado a distintos profesionales. Si bien el referente del presente texto es la propuesta fenomenológica existencial de Joanneliese de Lucas Freitas $(2013,2014)^{4}$, para comprender la historicidad del concepto y la naturaleza compleja del fenómeno es pertinente revisar ligeramente al menos tres de los discursos que otros enfoques han construido sobre él y que mantienen cierta vigencia.

En Duelo y melancolía, Freud (1993) define el duelo como una reacción ante la pérdida de un ser amado o de una abstracción, además, lo caracteriza por el dolor y la carencia de interés en el mundo exterior. Según Freud, el dolor está anclado en el anhelo y el duelo tiene como objetivo, luego de que se imponga la prueba de realidad, retirar las cargas libidinales del objeto perdido, causa fundamental del anhelo mismo, y ponerlas a disposición de la vida (Díaz, 2008).

Por otra parte, Worden (2013), citando a Bowlby, define el proceso de duelo como una reacción normal de los seres humanos ante la pérdida de

3 Las cifras de la Unidad de Duelo de la Funeraria San Vicente pueden tener algún sesgo menor dado que algunas de las personas no consultan por un duelo actual sino por lo que la literatura ha denominado duelo congelado o aplazado.

4 Joanneliese de Lucas Freitas es Magíster en Psicología del Desarrollo y Doctora en Psicología Clínica por la Universidad de Brasilia (UnB). Profesora adjunta y vicecoordinadora del Laboratorio de Fenomenología y Subjetividad (LabFeno) de la Universidad Federal de Paraná. Autora de diversos artículos sobre duelo y fenomenología y de los libros: Arte y psicología, Madres en luto, Experiencias de dolor y muerte y Psicoanálisis y fenomenología. 
una figura que satisfacía necesidades de seguridad y protección. Al igual que Freud, Worden considera que el proceso de duelo no se constituye por sí mismo como una desviación o una manifestación patológica, sino que es similar a una alteración de la normalidad y requiere de un proceso para retornar al equilibrio.

En Worden (2013) este proceso de recuperación del equilibrio tras la muerte de un ser querido se distingue porque, en las condiciones normales, requiere de la ejecución de cuatro tareas principales:

1. Aceptar la realidad de la pérdida.

2. Trabajar las emociones y el dolor de la pérdida.

3. Adaptarse a un medio en el que el fallecido está ausente.

4. Recolocar emocionalmente al fallecido y seguir viviendo (p. 15).

Denominar tareas a las acciones que el proceso de duelo involucra es un intento por proponer la constitución de una persona activa y responsable, más que de un mero ser pasivo al que el duelo simplemente le acontece.

Esta idea del rol activo de las personas en duelo coincide con algunos elementos de la propuesta de Robert Neimeyer (2002), sin embargo, este autor se distancia de un modelo normativo del proceso de duelo basado en experiencias individuales aisladas de todo contexto relacional y, en cambio, propone un modelo alternativo fundado en el constructivismo y la narrativa de la reconstrucción de significados frente a la pérdida. Planteamientos complejos como el constructivista llevan la reflexión a un punto en el que resulta imprescindible pensar en los horizontes históricos y las consideraciones sociales y familiares asociadas a la muerte y el duelo.

En la propuesta de Neimeyer, igual que en la psicología fenomenológica existencial, las pérdidas están enmarcadas en una serie de elementos que les dan uno u otro sentido. Estos sentidos son mencionados por Freitas (2014) en su texto $A$ maior dor do mundo: o luto materno em uma perspectiva fenomenológica: para ella, la manera en que se presentan las pérdidas, el horizonte histórico ligado a las consideraciones sociales y familiares sobre la muerte y el duelo, y el cambio abrupto de la relación yo-tú, son elementos por considerar 
La última visita del embajador: una aproximación clínica comprensiva a la experiencia [157] de duelo de una madre por su hijo en la ciudad de Medellín

cuando se comprende el sentido que las personas le dan a la muerte de sus seres amados.

Por ejemplo, nuestra sociedad les confiere a las madres unas responsabilidades asociadas al cuidado y las representa como figuras de resguardo y alivio, esto permite comprender por qué cuando un hijo fallece antes que una madre el suceso es evaluado comúnmente como causante de un dolor de una intensidad innombrable (Freitas, 2014).

Algunos autores como Freitas (2014), Brice (1982, 1991) y Martins (2001), afirman que la pérdida de un hijo es para las madres la experiencia de una promesa no cumplida y, por tanto, es representada por ellas como una pérdida de una parte de sí. Desde esta concepción, la pérdida de un hijo obliga a la madre a construir una nueva manera-de-ser yo-madre.

Es en este ámbito social y académico donde surge la pregunta que guía este artículo: ¿cómo atraviesa la experiencia de duelo una madre de la ciudad de Medellín durante el proceso de acompañamiento psicológico por la pérdida de su hijo?; y da lugar a los objetivos del mismo: comprender cómo vive una madre en la ciudad de Medellín la experiencia del duelo por su hijo en medio de su proceso de acompańamiento psicológico y relacionar esta vivencia con las propuestas de la psicoterapia existencial y la fenomenología, específicamente los planteamientos de Joanneliese de Lucas Freitas relacionados con la muerte y el duelo.

\section{Metodología}

La investigación aquí expuesta es un estudio de caso tipo diacrónico 5 : durante un tiempo determinado se siguió un caso para observar y comprender los cambios ocurridos en el participante (Scandar, 2014). Se realizó un proceso clínico bajo el modelo de intervención de la psicoterapia existencial, que aquí se entenderá como una mirada que privilegia una actitud terapéutica que se ocupa de los dilemas fundamentales de la existencia humana: la libertad, la

\footnotetext{
El trabajo fue valorado y aprobado por el Comité de ética de la Universidad San Buenaventura, sede Medellín. Se realizó el consentimiento informado con la usuaria y se resguardó la identidad de ella y su hijo fallecido, acorde con las disposiciones legales de la Ley 1090 de 2006 y la Ley 1616 de 2013.
}

DOI: https://doi.org/10.17533/udea.rp.v11n1a07 
muerte, el aislamiento y la carencia de sentido vital — que se distingue de la ejecución de técnicas-, y que está interesada en comprender al ser humano y su experiencia (Martínez, 2012). Este proceso de acompañamiento clínico tuvo una duración de 19 sesiones, cada una de 45 minutos, durante 9 meses, y se desarrolló en la ips Unidad de Duelo de la Funeraria San Vicente en Medellín, Colombia. Cada sesión fue grabada y al final del proceso se transcribieron estos registros y se cotejaron con los registros de la historia clínica. Valiéndose de la metodología fenomenológico-hermenéutica se obtuvieron las categorías emergentes que se expondrán más adelante.

Esta metodología para acercarse al fenómeno toma fundamentalmente la propuesta de Alberto de Castro. Según De Castro, Gordillo y Tamara (2007), el método fenomenológico prioriza la inmediatez de la experiencia del individuo, comprende el fenómeno desde la intencionalidad de quien lo vive y se interesa en hallar el significado, sin establecer relaciones causa y efecto.

A su vez, De Castro et al. (2007), citando a Dilthey, definen hermenéutica como un proceso a través del cual se accede a la vida psíquica del individuo, leyendo los signos que orientan el significado que éste da a los fenómenos.

Si bien el método fenomenológico-hermenéutico respeta la experiencia del coinvestigador y por lo tanto no intenta objetivarla, sí propone una serie de procedimientos para asegurar que la comprensión del proceso sea genuina, que van desde la familiarización hasta las conclusiones. De Castro et al. (2007) consideran los siguientes:

Familiarización — relectura de la entrevista transcrita para la comprensión del sentido total de la experiencia.

Transformación de la experiencia en Unidades de Sentido.

Categorización y subcategorización de las Unidades de Sentido.

Transformación —en lenguaje psicológico— de las Unidades de Sentido categorizadas.

Elaboración final de los resultados.

Devolución o retroalimentación final.

Conclusiones. 
La última visita del embajador: una aproximación clínica comprensiva a la experiencia [159] de duelo de una madre por su hijo en la ciudad de Medellín

\section{Precedentes}

\section{El dolor, el duelo y la relación}

Según el antropólogo francés Louis Vincent Thomas (1989), la muerte contemporánea se suele concebir como exterior, como ajena a la experiencia y posible sólo cuando es causada por una fuerza distinta y persecutoria ${ }^{6}$. Del mismo modo que Thomas (1989), Freitas (2013) se opone a esta concepción ingenua de la muerte como ente acechante y propone una concepción cuyo fundamento es el reconocimiento de la muerte como posibilidad que habita toda relación. La muerte es una experiencia que se hace propia y deja de ser concebida como una visitante inoportuna para considerarse como un elemento ontológico que se da a través de la relación que establecemos con aquellos con los que se existe. Para Thomas (1983), cuando se pierde a aquel con quien nos relacionábamos — tú- y, por ende, en quien nos veíamos representados - yo-, experimentamos la interioridad de la propia muerte, que ya no nos acecha, sino que nos habita.

En la propuesta de la psicoterapia existencial y la fenomenología se comprende la emergencia de la subjetividad como una intersubjetividad: el otro nutre mi ser-en-el-mundo. Freitas (2013) define la intersubjetividad, basándose en las propuestas de Merleau-Ponty, como aquello que precede la relación yo-tú, como una estructura de la vida que nos permite percatarnos que es en presencia del otro que aparecemos como personas. La intersubjetividad es inaugurada por la intercorporeidad, los cuerpos de los otros que pasan por los sentidos y posibilitan el encuentro yo-tú. Este encuentro es aquello que da sentido a nuestra experiencia en cuanto nos permite ser-en-el-mundo.

Esta importancia que se atribuye a la presencia del otro destaca cuando se pretende definir el proceso de duelo. Al ser el otro parte fundamental de mi existencia, su desaparición conlleva a que el campo existencial se transforme y sean necesarias nuevas formas de ser-en-el-mundo, es así como el proceso de duelo se pensará aquí como un proceso creativo que implica transformar

\footnotetext{
Un buen ejemplo de esto es la pintura Muerte y vida de Gustav Klimt, quien representa a la muerte como una entidad por fuera del entramado de la vida, atenta y acechante, y a la vida como un grupo de personas que se funden en un tranquilo sueńo.
} 
la relación con el tú perdido y construir un nuevo modo de ser. Este ejercicio creativo es motivado por una ausencia corporal que busca configurarse como una nueva presencia:

\footnotetext{
El "tú" no estará más presente en su corporeidad, con su voz, su tacto, su olor, su materialidad, sin embargo, no cesa de presentarse como parte de la existencia del enlutado: recuerdos, fotos, deseos, vidas y momentos compartidos hacen que el "tú" no cese totalmente de presentarse, sin embargo, no comparte más el mundo como un "otro yo mismo". La existencia será en adelante una presencia que se anuncia en ausencia. Lo que falta al enlutado, más que el "tú", es un modo habitual de ser "yo", un modo de ser-en-mundo, una infinidad de significaciones propias e inherentes a un campo relacional (Freitas, 2013, p. 19).
}

El mundo en el que el consultante está tras la pérdida es un mundo donde el tú que otrora lo constituía ya no es más cuerpo. Esta ausencia es narrada en el espacio clínico como una historia que deviene en sufrimiento y angustia.

\section{Horizonte histórico: la historia de arribo y la historia subjetiva}

El encuentro con la muerte produce en las personas un malestar que se ve reflejado en narraciones subjetivas cargadas de sufrimiento desde que su ser amado falleció. Al principio predomina el anhelo y el dolor: un dolor asociado a la necesidad de recuperar algo que se considera perdido, una necesidad de llenar un espacio que, según su relato, quedó vacío (Díaz, 2008). Este vacío es la manifestación de la pérdida de la intersubjetividad revelada a tal punto que es común que el consultante la ubique en el cuerpo y afirme "sentirse vacío".

Tales sensaciones son posibles en el marco de un grupo que le da significado y un horizonte que lo define (Freitas, 2013). El horizonte histórico no es sólo una manera de ver la forma reciente en que aparecen los fenómenos, sino una mirada a las posibilidades de éste y sus respectivas articulaciones de sentido. Si bien el horizonte no determina a las personas, sí es condicionante, lo que revela que su implicación en la historia subjetiva y en el sentido sea ineludible (Freitas, 2013). Así, el concepto que nuestra cultura tiene hoy de la muerte se asocia con un horizonte histórico que nos rodea. 
La última visita del embajador: una aproximación clínica comprensiva a la experiencia [161] de duelo de una madre por su hijo en la ciudad de Medellín

Según Aries (2000), han existido cuatro actitudes frente a la muerte desde la Edad Media: la muerte domesticada —Edad Media—, una muerte esperada porque era un destino colectivo que se atravesaba en una ceremonia pública y organizada; la propia muerte — siglos xii-xiii-, una muerte que individualiza la experiencia a través de la importancia concedida al juicio final ${ }^{7} \mathrm{y}$ al valor crucial de las últimas horas del moribundo ${ }^{8}$; la muerte del otro — siglo XVIII-, el hombre de esta época exalta la muerte, la dramatiza y se ocupa ya no de su propia muerte, sino de la muerte de los otros. Es en ese siglo que los grandes relatos que sostenían la sociedad empiezan a resquebrajarse. De los testamentos desaparecen las cláusulas piadosas, las misas mandadas y las limosnas, dejando única y exclusivamente las disposiciones sobre los bienes materiales del difunto. A partir de esta transformación, el luto del siglo XIX muta en un luto singular, ya no regido por tradiciones o costumbres, sino por una respuesta a "una honda herida" (Aries, 2000, p. 64) que produce llanto, desmayos y gritos. Se inaugura lo que en historia de la muerte en Occidente será llamado: una intolerancia a la separación (Aries, 2000).

La Modernidad, pues, crea una actitud ante la muerte acorde con sus valores - la muerte vedada del siglo XIX- y pone sobre la muerte el manto del tabú. Para Aries (2000), la muerte moderna se constituye en un problema porque el sentimiento de aflicción cuestiona la idea de bienestar constante que reina en la época, los rituales se van suprimiendo y pierden la carga dramática, la persona se muere en el hospital y no en casa, el sufrimiento es censurado y la expresión de dolor ya no inspira piedad, sino que se convierte en signo de repugnancia o enfermedad.

Estas actitudes están relacionadas con las tradiciones religiosas que se han ocupado de entender la trascendencia a través de los años, empero, otra de las características de la Modernidad, que ya se venía vislumbrando desde el siglo XVIII, es la decadencia del cristianismo. Con el decaimiento de estos metarrelatos, el ser humano se ve abocado a enfrentar la construcción de historias

Aries atribuye esto a que los religiosos de la época empiezan a interpretar la muerte más desde el Evangelio según Mateo que desde el Apocalipsis.

8 Aries sugiere observar el ars moriendi de la época para comprender gráficamente la idea según la cual el moribundo era testigo de las tentaciones demoníacas y la presencia de la Trinidad en lados opuestos de su lecho final. 
particulares que ocupen el lugar de los que antes lo sostenían. Bedoya (2010), citando a Vattimo, dice:

Final de la historia significa final del historialismo, o sea, de la comprensión de las vicisitudes humanas como estando insertas en un curso unitario dotado de un sentido determinado, el cual, en la medida misma en que viene a ser reconocido, se devela como sentido de emancipación (p. 72).

Así, el proceso de duelo contemporáneo puede pensarse como un intento de construir historias posteriores a la muerte de un ser amado que obedezcan a las subjetividades y permitan, ya no retomar los metarrelatos, sino crear nuevas maneras de ser.

Esta comprensión del horizonte histórico distingue la lectura que se hace de un caso clínico desde una mirada explicativa o descriptiva - modelos de fases, tareas o etapas individuales - y la contrasta con la concepción de la experiencia de duelo como ontológica y relacional, lo cual convierte la comprensión del proceso de duelo en un ejercicio hermenéutico. Bedoya (2010), refiriéndose a la posibilidad hermenéutica de la psicoterapia, lo expone del siguiente modo:

El éxito de la intervención clínica consistiría en que el consultante con su historia de arribo devenida en sufrimiento y padecimiento, gracias a la labor hermenéutica de la clínica psicológica, teja una historia de sí, reconozca que siempre estará inacabada y en trámite, y, finalmente, disminuya su sufrimiento (p. 8).

Estas propuestas teóricas sustentan no sólo una particular visión del hombre contemporáneo y una actitud frente a la muerte, sino que posibilitan la intuición inicial que guía este ejercicio: la experiencia de duelo tal vez no se pueda normalizar, porque es esencialmente relacional y su desarrollo probablemente linde con la posibilidad de incluir a quien deja de existir encarnadamente en el relato íntimo de la existencia de quien sobrevive. 
La última visita del embajador: una aproximación clínica comprensiva a la experiencia [163] de duelo de una madre por su hijo en la ciudad de Medellín

\section{El arribo: perfil de la consultante y descripción inicial del caso}

María9 es una mujer de 45 años, residente en la ciudad de Medellín, casada, y madre de dos hijos. Para la fecha de su primera sesión había atravesado el duelo por su abuela y por el padre de sus dos hijos.

La paciente, a quien para proteger su identidad llamaremos María, llega al espacio clínico narrando que, dos meses antes, su hijo de 26 años había fallecido en medio de un viaje. Su demanda consistía en aliviar una "sensación de dolor que nunca había sentido" 10 , en "dejar de llorar" y en poder hablar de "un sentimiento de culpa" que la aquejaba debido a que "la muerte es muy injusta porque acaba con los sueńos".

El joven era un politólogo y estudiante de derecho que disfrutaba viajar y bailar, era amigable y estaba vinculado a actividades culturales y voluntariados en organizaciones no gubernamentales. Estando en un país de Latinoamérica con su abuela, sufrió un fuerte dolor de cabeza, en el hospital le recetaron analgésicos y al regresar al hotel e ingerirlos empezó a vomitar, a sentir escalofríos y convulsionar; finalmente perdió la conciencia y murió algunos días después a causa de una meningitis.

Cuando María tenía 16 años y sus padres se habían acabado de divorciar, sostuvo relaciones sexuales con su novio y sin su consentimiento éste eyaculó dentro de ella. Dos meses después descubrió su embarazo y le contó a su pareja. Según su relato, su novio la maltrató verbalmente y le sugirió abortar, a lo que ella se negó rotundamente. Cuando María le contó a su padre, éste le dejó de hablar y sólo lo volvió a hacer cuando nació el niño. Por último, le comentó la situación a su madre y a su abuela, con quienes convivía, y ellas, aunque tristes, le manifestaron su apoyo. Al respecto María dice: "Yo creo que, en el fondo, él — refiriéndose a su hijo— supo que yo lo había aceptado cuando nadie más lo había hecho".

Después de un par de semanas, su pareja decide apoyar a María e incluso se muda a vivir con ella y la acompaña en todo el proceso de gestación del

\footnotetext{
Nombre alterado para proteger la identidad de la consultante.

10 La paciente, para proteger su identidad será llamada María y lo expresado hace parte la comunicación personal durante la psicoterapia desarrollada en 2018.
} 
niño. A partir de este momento llamaremos al hijo de María: Juan. Dos años después de que Juan hubiera sido concebido, nace una segunda hija. El vínculo conyugal es abruptamente roto porque el padre de los niños es asesinado cuando Juan tiene aproximadamente 5 años, por lo cual María se ve obligada a iniciar su vida laboral mientras su madre y su abuela cuidan a sus dos hijos. Respecto a la relación construida con Juan, María dice: "Él siempre me acompañaba en todo. Teníamos una relación que no necesitaba palabras".

Por su parte, la relación con su hija, vínculo que en la actualidad mantiene su yo-madre, sólo aparece en el espacio cuando ella refiere que ha venido teniendo dificultades con ella porque se molesta por ver a María llorando.

Durante los primeros encuentros la paciente se ocupa de describir la historia que había tenido con su hijo hasta el momento de su muerte y el dolor que siente por no tenerlo. Además, señala sus inconvenientes para conciliar y mantener el sueño y vivir una sensación constante de anhedonia, no sólo en su trabajo sino en la mayoría de las actividades cotidianas.

En la primera cita se realiza un encuadre contemplando los elementos centrales consignados en la Ley 1090 de 2006 y el Código Deontológico y Bioético para el ejercicio de la profesión de Psicología en Colombia (2009). Por consideraciones éticas se socializa con la paciente el consentimiento informado para documentar, grabar y publicar los resultados de la profundización en la que el caso será comprendido.

\section{Discusión: emergencia de un nuevo ser en el mundo}

Tal y como el método fenomenológico hermenéutico lo indica, la experiencia atravesada por María en su proceso clínico será descrita a partir de categorías resultantes, luego de hacer un ejercicio comprensivo.

En el actual estudio de caso se encontraron siete categorías, de las cuales seis coinciden con lo hallado por Freitas (2014) en su texto: El dolor más grande del mundo: el duelo materno en una perspectiva fenomenológica. Freitas describe allí diez categorías que dan cuenta de cómo se da el proceso de duelo en madres en Brasil que han perdido sus hijos: (1) dolor, (2) pérdida de un modo de existir, (3) vivencia espiritual, (4) culpa, (5) pérdida de sentido del 
La última visita del embajador: una aproximación clínica comprensiva a la experiencia [165] de duelo de una madre por su hijo en la ciudad de Medellín

mundo-de-la-vida, (6)voluntad de morir, (7) fragmentación de los vínculos afectivos, (8) compromiso en proyectos que tuvieran relación con el hijo, (9) perpetuación de la memoria del hijo y (10) estrechamiento de lazos con las personas significativas para el muerto.

\section{Dolor}

De acuerdo con Freitas (2014), las madres relatan que el dolor tras la pérdida de un hijo es intenso, imposible de comparar y profundamente particular. Esto, según ella, obedece a que culturalmente a las etapas biológicas de la maternidad — gestación, alumbramiento y lactancia — se le concede una condición especial que garantiza la unidad con el hijo incluso después del parto. Esta idea confiere a la relación madre-hijo el carácter de extraordinario, casi como si el hijo fuera parte del cuerpo de la madre toda la vida (Martins, 2001). Además, históricamente se ha considerado la relación yo-tú —madre-hijocomo una relación estructurante del sentido vital de la madre, entre otras cosas porque nuestra cultura les ha atribuido la función de cuidado y protección permanente. En el estudio de caso, es posible observar que María da cuenta de esta sensación de relación extraordinaria con su hijo en las siguientes verbalizaciones: "Yo desde que tuve el encuentro sexual supe que estaba en embarazo", "[y]o creo que él supo que yo lo había aceptado cuando nadie lo había hecho"; mientras que el dolor por la ruptura del vínculo lo describe así: "Nunca he sentido un dolor como este, es como un vacío", “¿[u]no se queda toda la vida en duelo? Es que yo siento el dolor de mi hijo tan adentro".

Una de las posibilidades asociadas a que la figura de la madre se haya erigido como símbolo de protección consiste en que al verse comprometida la integridad del hijo o ante la muerte de éste, se cuestione el sentido de la relación y se asuma el fallecimiento como una falla en la función materna (Alarcão, De Barros Calvalho y Pelloso, 2008). Esta experiencia produce cuestionamientos y recriminaciones que devienen en sentimientos de profunda culpa, lo cual fue posible percibir en María en algunas verbalizaciones que denotan este sentir: 'La muerte es muy injusta. Él tenía muchos sueños, es muy injusto lo que le pasó. No sé si yo debí dejarlo ir por allá”. 
En el caso de María, esta culpa no parece obedecer a una asociación racional que establezca una relación causa y efecto entre la muerte de su hijo y el consentimiento que ella pudo o no haber dado para la realización del viaje, sino a la fantasía reminiscente de su lugar simbólico como refugio, por lo cual, frente al decaimiento de esta ilusión, María se asume como determinante en un acontecimiento en el que su consideración era intrascendente.

Durante el acompańamiento psicológico, la relación de la paciente con el dolor y la culpa es usada por ella como un medidor de avance en su proceso. Incluso, en las últimas sesiones verbaliza que: "En este momento sufro de manera diferente. Yo he entendido que el dolor no se me va a quitar".

Esta resignificación del dolor es una de las experiencias que María vivió, teniendo en cuenta que su motivo de consulta inicial era "querer dejar de llorar" y que después de experimentar e intentar nombrar su dolor, incluye dentro de su nuevo ser-en-el-mundo la manifestación de este, sin castigarlo ni asociarlo con debilidad como en su historia de arribo.

\section{Pérdida de sentido en el mundo de la vida y pérdida de un modo de existir}

Como se ha dicho anteriormente, la muerte es vivida por el deudo como una pérdida de un modo de relación, dada la aparición del cadáver; tras ello se da el rompimiento de la intercorporeidad y la intersubjetividad y el deudo pierde su sentido-del-mundo-de-la-vida y se ve abocado a la creación de uno nuevo (Brice, 1991; Freitas, 2013). Igual que en los casos descritos por Freitas (2014) y Brice (1991), María experimentó estremecimiento y sensaciones de pérdida de perspectiva y sentido luego la muerte de Juan:

Estoy teniendo problemas en la oficina y con mi hija. Yo no sé, mira que desde que Juan se murió yo pienso en el día en que me vaya a morir y no tengo ningún problema con eso, yo primero pensaba en la muerte y decía: “¡Ay, no, qué miedo morirme!". Ya no.

En esta verbalización aparece la muerte, posibilidad entre todas las posibilidades y fin del ser-en-el-mundo, como un horizonte contemplado por 
La última visita del embajador: una aproximación clínica comprensiva a la experiencia [167] de duelo de una madre por su hijo en la ciudad de Medellín

María. La literatura fenomenológica del duelo asocia este tipo de ausencias de sentido en el mundo de la vida y del modo de existir a vínculos en los que el sentido vital del deudo está depositado notablemente en el fallecido (Brice, 1991; Freitas, 2013). En el caso de María su primogénito era el depositario de sentimientos y afectos muy importantes, con lo que se reivindica la condición relacional de la muerte propuesta por Thomas (1983) y Freitas (2013, 2014), según la cual construimos nuestro ser en el mundo a través de la relación con el otro; por ende, la muerte de su hijo es una pérdida de un modo de ser en el mundo. Freitas (2014) sostiene que de lo que carece el enlutado, más que del tú, es de su modo de ser yo, carece de los significados que le eran propios y que provenían de la relación.

La dimensión creativa del proceso de duelo consistirá entonces en crear un nuevo modo-de-estar-en-el-mundo y con él un nuevo sentido; sin embargo, antes de lograr este cometido final el yo-madre, en este caso María, experimenta una serie de vivencias singulares: voluntad de morir, fragmentación de los vínculos afectivos, perpetuación de la memoria del hijo y vivencia espiritual, que parecen ser necesarias para la consolidación de una historia subjetiva que soporte el nuevo-ser-en-el-mundo.

\section{Voluntad de morir}

Al morir Juan, María siente que su mundo colapsa. Se ha mencionado anteriormente lo definitivo que resulta el relacionamiento intercorporal para la intersubjetividad y la construcción del yo: cuando María siente que con la muerte de Juan su modo-de-ser-en-el-mundo y su sentido ya no le son suficientes, se acerca a la posibilidad de la muerte, bien sea para reencontrarse con Juan o como una respuesta a la falta de perspectiva y sentido (Freitas 2014). En la siguiente narración María refleja la primera de las opciones: "Siento que me hace mucha falta y que lo tengo ahí conmigo y que algún día yo espero verlo, yo espero que sí haya otra vida después de la muerte”, y en este fragmento evidencia la segunda: "Ahora [llanto], yo porque sé que cuando uno se muere le deja un hueco horrible a los que están vivos, pero ya ni me importa”. 
Para Freitas (2014) y Martins (2001), las implicaciones del rompimiento de la relación yo-tú llevan a la madre a anhelar un reencuentro con el hijo perdido. Este reencuentro sólo es posible en los metarrelatos religiosos, y eso da sentido a que María aluda a la trascendencia como esperanza de reencuentro. Además, la pérdida de un hijo es representada como una promesa - te cuidaré, te protegeré y partiré primero- a la que se falló, como el rompimiento de un sueño y el fin de las expectativas puestas en él. En el caso de María, esta experiencia es verbalizada así: "Él decía que no quería, pues que él no quería morirse antes de... de verme morir a mí, él decía que él prefería morirse antes de verme morir a mí", "[y]o hubiera preferido morirme primero como es la ley de la vida”.

Usualmente, la voluntad de morir se ha asociado en contextos clínicos con ideaciones suicidas y se la ha considerado como un indicador de trastorno o desajuste; en el caso de María, la voluntad de muerte responde más al enfrentamiento con la pérdida que a una patología o intención autolesiva.

\section{Fragmentación de los lazos afectivos}

La singularidad de la relación entre María y su hijo era de tal magnitud que ante la pérdida su dolor es imposible de comprender para los demás, lo que es coherente con la descripción de la muerte moderna de Aries (2000). Este fragmento de una sesión con María evidencia esta experiencia: “Tuve un problema con mi hija, me dijo que yo lo único que hacía era llorar por mi hijo muerto y me había olvidado de ella que estaba viva”.

Freitas (2014) señala que frente a la pérdida de un ser querido las madres pueden experimentar soledad y silencio proveniente de su entorno. En el caso de María, la soledad tiene lugar en el sentido de que nadie parece comprender su dolor, vive una experiencia única que nadie en el mundo puede vivir con ella y experimenta la pérdida de un vínculo que a sus ojos era excepcional; inclusive, cuando se sustituye el silencio aparece una reclamación de parte de su hija en la cual reivindica su vitalidad y pide para ella una atención que considera merecer. Ante esta petición María reacciona con ira y expresa: "Yo creo que ella no me entiende, ella no puede entender lo que es esto". 
La última visita del embajador: una aproximación clínica comprensiva a la experiencia [169] de duelo de una madre por su hijo en la ciudad de Medellín

Tras profundizar en su horizonte histórico, se percata de que, durante la vida de sus dos hijos, Juan tuvo siempre una posición preponderante. Siempre se destacó por sus logros académicos y sus múltiples intereses, mientras que su hija no recibió nunca la valoración que ahora, cuando éste ya ha muerto, solicita. María nombra este nuevo elemento del siguiente modo:

\footnotetext{
¡Ay, qué pesar de mi niña! Ella tuvo que ir por el cuerpo de Juan, yo no sé yo que hubiera hecho sin ella en esos momentos. Pero vea cómo es la vida, hasta en la muerte este muchacho se hizo el importante, se muere por allá y nos pone a hacer todo esto a nosotros.
}

De esa manera, la solicitud de la hija de María no está únicamente sostenida en que el llanto de su madre le resulte incómodo en términos de la concepción de la muerte moderna y la censura a la aflicción, sino que ese llanto era interpretado por ella como una repetición de su papel secundario respecto a su hermano mayor. La fragmentación del vínculo, en este caso denunciada por María y su hija, está, paradójicamente, al servicio de un encuentro entre el yo-madre - tanto de un hijo muerto como de una hija viva - y el tú-hija. Sólo después de esta fragmentación y su posterior conciliación fue posible que emergiera una imagen de Juan capaz de ser integrada en la naciente historia subjetiva de María.

\section{Perpetuación de la memoria del hijo}

Freitas (2014), coincidiendo con Giannini (2011) y Martins (2001), sostiene que las madres tienen dos intereses fundamentales respecto a la memoria del hijo: que no sea olvidado y que se lo recuerde haciendo énfasis en sus características positivas. En el caso de María esto se observa cuando ella refiere que: "Él quiso siempre estudiar ciencias políticas. Quería trabajar en eso y ayudar a todo el mundo, quería llevar por el mundo cosas buenas de Colombia. Él fue como un embajador, tenía muchos sueños".

Los autores tienen posturas divididas frente a si la perpetuación de la memoria del hijo es una resignificación de la relación yo-tú que preserva lo significativo y permite el vínculo a pesar de la pérdida de la intercorporeidad, o 
un momento del proceso de duelo que de manera opuesta evita resignificar la pérdida y lleva al tú hacia la idealización. Gudmundsdottir y Chesla, como se cita en Freitas (2014), presentan estas prácticas de memorialización como elementos de resignificación que contribuyen al mantenimiento del vínculo entre el yo-madre y el tú-hijo aun después del fallecimiento. Gudmundsdottir y Chesla (2006) incluyen dentro de estas prácticas los rituales funerarios y los homenajes póstumos. En el caso de María esto es patente:

Todo fue tan bonito. Fue como dejarlo ir. Eso lo hace a uno descansar porque es saber que tantas personas amaron a su ser querido. Desde Chile vino gente a su velorio y los que no pudieron venir mandaron videos. Hicieron un recordatorio con forma de mapamundi y le construimos un video con fotografías de sus viajes. A mi Juan lo querían mucho, él era muy querido, muy servicial y le gustaba ayudar a todo el mundo.

Lo encontrado en esta investigación no es suficiente para concluir que la perpetuación de la memoria está asociada a la resignificación de la relación o lo opuesto; sin embargo, un criterio útil para comprender estas vivencias es la inclusión dentro de la memoria de los defectos del fallecido como señales contrarias a la idealización. En el caso de María, nombrar a su hijo como "embajador" le permitió resignificar elementos que en su historia de arribo eran percibidos como "injustos" y devenían en sufrimiento a causa de la imposibilidad de relacionarse con Juan, dada la pérdida de la intercorporeidad. Cuando lo nombra embajador, carga esta palabra de significados y asume que su nuevo-ser-en-el-mundo será ser la madre de un hijo muerto que 'llevó amor a donde estuvo": "Mi hijo fue un embajador de amor", "era muy testarudo, comprenderlo era difícil [...]. Si hubiera logrado ser el embajador del país hubiera logrado hacer muchas cosas".

La preocupación por sostener el recuerdo de su hijo y por la manera en que será recordado es un intento de construcción de un lugar para el fallecido en el mundo de los vivos; no obstante, en los estudios de Freitas (2014) las madres también reportan una serie de pensamientos asociados a la trascendencia o la vivencia espiritual y en el caso de María ello también ocurrió. 
La última visita del embajador: una aproximación clínica comprensiva a la experiencia [171] de duelo de una madre por su hijo en la ciudad de Medellín

\section{Vivencia espiritual}

María es una mujer formada en el catolicismo y, como se ha mencionado anteriormente, este metarrelato ha venido decayendo. No obstante, María encuentra en su dogma religioso un mecanismo para paliar el dolor de la pérdida, una esperanza de restablecimiento del vínculo anterior y un sentido a la muerte de Juan:

Yo espero verlo, yo espero que sí haya otra vida después de la muerte [...] Gracias a Dios se fue de esta manera: todo se dio, incluso su muerte quedó registrada en la notaría donde se registran las defunciones de personas importantes. Qué vida tan bendecida la de mi hijo.

Freitas, citando a Alarcão y Pelloso (2008) y Gudmundsdottir y Chesla (2006), concluye respecto a la espiritualidad que es una posibilidad de vínculo ante el rompimiento de la intercorporeidad, pues la espiritualidad intenta mantener la relación yo-tú, vivida con anterioridad en lo cotidiano, en el plano de lo trascendental.

\section{Conclusiones: el duelo como proceso creativo y la construcción de la historia subjetiva}

Después de que María experimentara las vivencias descritas en las categorías anteriores, en su proceso psicológico emergieron una serie de resignificaciones que se diferenciaban de lo narrado por ella en los primeros encuentros.

La historia de arribo de María, es decir, la historia con la que llegó al espacio estaba marcada por los horizontes históricos que la rodeaban, predominaban la sensación de injusticia y el dolor asociados con el sentir de que como madre había fallado en la promesa fundamental de cuidar a su hijo y que, por lo tanto, su sentido, definido en gran parte por su vínculo con Juan, estaba condenado a la imposibilidad. Su época la había influenciado a tal punto que su propio sufrimiento, expresado a través del llanto, le resultaba incómodo y reprochable. Durante los diferentes momentos de su proceso clínico María confrontó estos elementos centrales de su historia de arribo y los enriqueció 
con narraciones y datos que al comienzo no le era posible escuchar; esta verbalización refleja este hecho:

\begin{abstract}
Ayer por primera vez pude hablar bien con mi mamá y escuchar la culpa que ella sentía, a ella le ofrecieron devolverse a Colombia y ella no quiso. Nunca me lo dejó solo. Es que eso se cuenta y se recuenta y uno como que no se da cuenta.
\end{abstract}

No es que los datos no estuvieran disponibles para María — como se dijo antes, ella vive con su madre y la posibilidad de hablar de lo sucedido era cuando menos cercana-, pero sólo hasta ese momento, cuando ya había logrado deshacerse de los metarrelatos que el horizonte histórico le proponía y estaba dispuesta a construir su propia historia de lo sucedido, escuchó la narración de su madre.

Según Freitas $(2014,2013)$, el duelo es experimentado como una pérdida de un modo de relación y, por consiguiente, dado que la subjetividad es resultado de la intersubjetividad, también se pierde el sentido del mundo-dela-vida, obligando así al doliente a atribuirle un nuevo significado a la relación y un nuevo sentido a su existencia. Para este fin se ha descrito anteriormente el papel fundamental que desempeña la memoria y la vivencia espiritual y habría que agregarle en este momento la capacidad de construir una historia propia de lo acontecido que permita la presencia interna del fallecido en paz y posibilite la creación de nuevos vínculos con él y con los otros — como lo vemos en Kovacs, como se cita en Freitas (2014)—. María, refiriéndose a este proceso, afirma lo siguiente:

Mi hijo fue feliz, tal vez vivió su vida así porque sabía que la vida es corta. Desde que yo lo eduque lo hice con amor y libertad, él me decía que quería viajar y yo hasta me endeudaba para que pudiera hacerlo [...] La relación que me queda para tener con él es seguirlo recordando. Me hace mucha falta, pero a veces, pienso cosas bonitas... se murió como un héroe, viajando como él quería.

No es posible afirmar que el dolor de María haya desaparecido a partir de la creación de una historia propia sobre la muerte de Juan, ni es interés de este trabajo determinar en términos normales o anormales su vivencia de duelo: ella misma nombró su dolor como "diferente" al final de su proceso y, 
La última visita del embajador: una aproximación clínica comprensiva a la experiencia [173] de duelo de una madre por su hijo en la ciudad de Medellín

tal como inició, el vínculo terapéutico terminó por su propia voluntad. Lo aquí expuesto concuerda con la literatura anterior: los hallazgos de las investigaciones en el duelo desde la fenomenología y la psicología de Brice (1982), Martins (2001) y Freitas $(2013,2014)$, las aportaciones de la antropología de Thomas (1983) y Aries (2000) y la propuesta de Bedoya (2010) de lo clínico como un proceso capaz de producir una historia subjetiva; todo ello, afirmamos, permite comprender la vivencia de duelo de una madre por su hijo como una experiencia creativa que invita al doliente a construir, de manera casi ineludible, una relación nueva con el fallecido y con el mundo.

Como una consecuencia derivada de este estudio se propone como tema de interés para futuras investigaciones indagar por la relación entre el cuerpo de la madre y la vivencia de duelo, dado que la asociación entre la pérdida de un hijo y la vivencia somática aparecen como una experiencia tanto en Martins (2001) como en la presente indagación.

La comprensión de la experiencia de pérdida a través del proceso psicológico de María propone pensar que el deseo de muerte y el anhelo de reencuentro en la trascendencia con el ser querido, no es necesariamente indicador de trastorno, sino un efecto de la pérdida de sentido y un anhelo de recuperar una relación que se rompió ominosamente. Según lo encontrado, la vivencia espiritual y la perpetuación de la memoria por medio de las narraciones, los rituales y los homenajes póstumos, facilitan la construcción de una nueva relación con el mundo y la emergencia de una historia subjetiva que, cuando menos, responsabilice al deudo de su pena.

\section{A María toda la gratitud y a Juan el eterno amor de su madre.}

\section{Referencias}

Alarcão, A., De Barros Calvalho, M., y Pelloso, S. (2008). A morte de um filho jovem em circunstância violenta: compreendendo a vivência da mãe. Revista Latino-Americana de Enfermagem, 16(3), 341-347.

Aries, P. (2000). Historia de la muerte en Occidente desde la Edad Media hasta nuestros días. Barcelona: El Acantilado. 
American Psychiatric Association. (2014). Manual diagnóstico y estadístico de los trastornos mentales. Bogotá: Panamericana.

Bedoya, M. (2010). La construcción de la historia subjetiva en la clínica psicológica. Acta Colombiana de Psicología, 13(1), 71-78.

Brice, C. (1982). Mourning throughout the life cycle. American Journal of Psychoanalysis, 42, 315-326.

Brice, C. (1991). What forever means: an empirical existential-phenomenological investigation of maternal mourning. Journal of Phenomenological Psychology, 22, 16-38.

Colegio Colombiano de Psicólogos. (2009). Código deontológico y bioético del ejercicio de la psicología en Colombia. Bogotá: Colegio Colombiano de Psicólogos.

Colombia. Congreso de la República. (2006). Ley 1090 de 2006: por la cual se reglamenta el ejercicio de la profesión de Psicología y se dicta el Código Deontológico y Bioético y otras disposiciones. Bogotá: Diario Oficial de la República de Colombia.

De Castro, A., Cardona, E., Gordillo, M., y Támara, S. (2007). Comprensión de la experiencia de la ansiedad en un estudiante que pertenece a un grupo artístico de la Universidad del Norte de la ciudad de Barranquilla. Psicología desde el Caribe, 19, 49-80.

Díaz, V. (2008). Del dolor al duelo: límites al anhelo frente a la desaparición forzada. Affectio Societatis, 9, 1-20.

Freitas, J. (2013). Luto e Fenomenología: uma Proposta Compreensiva. Revista da Abordagem Gestáltica, 19(1), 97-105.

Freitas, J. (2014). A maior dor o mundo: o luto materno em uma perspectiva fenomenológica. Psicología em Estudo, 19(2), 273-283.

Freud, S. (1993). Obras completas. Tomo xiv. Buenos Aires: Amorrortu Editores.

Giannini, G. (2011). Finding support in a field of devastation: Bereaved parents> narratives of communication and recovery. Western Journal of Communication, 75(5), 541-564.

Gudmundsdottir, M., \& Chesla, C. (2006). Building a new world: habits and practices of healing following the death of a child. Journal of Family Nursing, 12, 143-164.

Martínez, Y. (2012). Filosofía existencial para terapeutas y uno que otro curioso. México: Ediciones lag. 
La última visita del embajador: una aproximación clínica comprensiva a la experiencia [175] de duelo de una madre por su hijo en la ciudad de Medellín

Martins, G. (2001). Laços atados: A morte do jovem no discurso materno. Curitiba: Moinho do Verbo.

Neimeyer, R. (2002). Aprender de la pérdida. Barcelona: Paidós.

Payás, A. (2010). Las tareas del duelo: psicoterapia de duelo desde un modelo integrativo relacional. Barcelona: Paidós.

Scandar, M. (2014). El uso del estudio de casos en la investigación en psicoterapia. Psicodebate, 14(1), 69-84.

Seccional de Salud y Protección Social de Antioquia [DSSA]. (mayo de 2018). Mortalidad general por subregión/municipio 2005-2017. dssa. Recuperado de https:// www.dssa.gov.co/index.php?option=com_k2\&view=item \&id=78: ortalidad-general-por-subregion-municipio-2005-2017\&Itemid=120

Thomas, L. (1983). Antropología de la muerte. México: Fondo de Cultura Económica.

Thomas, L. (1989). El cadáver: de la biología a la antropología. México: Fondo de Cultura Económica.

Unidad de Duelo. (2017). Informe de gestión. Medellín: Unidad de Duelo.

Worden, W. (2013). El tratamiento del duelo. Barcelona: Paidós. 